Archives

$6 \mid 1990$

Varia

\title{
L'existence de forets dans les zones de lœss en chine ancienne
}

\section{Georges Metailie}

\section{OpenEdition}

\section{Journals}

Édition électronique

URL : http://journals.openedition.org/ccrh/2867

DOI : $10.4000 /$ ccrh.2867

ISSN : 1760-7906

Éditeur

Centre de recherches historiques - EHESS

Édition imprimée

Date de publication : 15 octobre 1990

ISSN : 0990-9141

Référence électronique

Georges Metailie, "L'existence de forets dans les zones de lœss en chine ancienne », Les Cahiers du Centre de Recherches Historiques [En ligne], 6 | 1990, mis en ligne le 20 mars 2009, consulté le 21 avril 2019. URL : http://journals.openedition.org/ccrh/2867; DOI : 10.4000/ccrh.2867

Ce document a été généré automatiquement le 21 avril 2019.

Article L.111-1 du Code de la propriété intellectuelle. 


\title{
L'existence de forets dans les zones de loss en chine ancienne
}

\author{
Georges Metailie
}

1 Lors de la cinquième Conférence Internationale sur l'Histoire des Sciences en Chine (San Diego, USA, 5-10 août 1988), le Professeur WU Deduo, de Shangaï, spécialiste de l'histoire de l'agriculture chinoise, a présenté un « Aperçu de la situation des forêts dans le bassin du Fleuve Jaune dans l'Antiquité $»^{1}$ dont je me propose de donner les grandes lignes suivies d'une appréciation personnelle.

2 Rappelant la controverse qui opposa, au cours des années trente, Marcel Granet et Ding Wenren, l'auteur considère que les deux points de vue subsistent aujourd'hui. Si l'on part de l'hypothèse selon laquelle «la Chine du Nord à la période antique était densément couverte de forêts » (M. Granet), la question inévitable à laquelle on doit répondre est : "Comment la végétation du bassin du Fleuve Jaune a-t'elle pu devenir ce qu'elle est aujourd'hui ?» Tant chez les spécialistes chinois qu'étrangers, on s'accorde pour parler de déboisement, les modalités et les raisons avancées variant selon les auteurs: expansion de l'agriculture, éloignement des bêtes féroces, incendies destinés à favoriser la chasse dans les zones montagneuses (Grande Muraille en particulier), abattage pour les constructions ou le combustible (chauffage et cuisine); d'aucuns incriminent la confection des cercueils, d'autres parlent de guerres et d'incendies.

3 Reconnaissant que tous ces facteurs ont pu conduire à la gravité de la situation actuelle du couvert végétal dans le bassin du Fleuve Jaune, l'auteur insiste sur la question cruciale à ses yeux de savoir si cette situation a bien été modelée par des facteurs humains, ou s'ils ne sont que secondaires, ce qui revient à poser la «vieille, importante et intéressante question» de la forme originelle de cette végétation. Pour ce faire, l'auteur choisit de se fonder exclusivement sur les sources anciennes écrites chinoises. Ici surgit un problème important, celui de l'identification des plantes citées dans ces textes et de la valeur de ces informations aux yeux des botanistes modernes. C'est finalement une approche plus écologique qui sera choisie. Analysant le Shan Hai Jing ${ }^{2}$, (entre le $\mathrm{v}^{\mathrm{e}}$ et le $\mathrm{II}^{\mathrm{e}}$ siècle A.J.C.), l'auteur note, pour 296 montagnes mentionnées, si l'on fait référence $1^{\circ}$ ) à l'existence de 
nombreux arbres et bambous ${ }^{3}, 2^{\circ}$ ) à la présence d'arbres, $3^{\circ}$ ) à l'absence de plantes, ou si 4 $\left.{ }^{\circ}\right)$ il n'y a pas de référence à la végétation. Ce dernier cas concerne $40 \%$ des montagnes. Prenant en compte les trois cas précédents, il conclut à la présence de forêts dans $60 \%$ de la zone, 40 \% étant sans végétation.

Pour ma part, deux faits me semblent aller dans le sens des conclusions de l'auteur: l'importance des ovins dans la proto-histoire chinoise, mise en évidence par J. Gernet ${ }^{4}$ à partir de critères philologiques, et la présence de rhinocéros ${ }^{5}$ laissent supposer une végétation de type savane. La présence des éléphants qui est également attestée ${ }^{6}$, indique que les arbres devaient toutefois être assez abondants. Notons enfin que les travaux de Zhu Kezhen sur l'histoire du climat en Chine ${ }^{7}$ suggèrent qu'au début de la dynastie des Zhou (-1066), la température moyenne dans la vallée du Fleuve Jaune était de $2^{\circ} \mathrm{C}$ supérieure à celle d'aujourd'hui.

\section{NOTES}

1. L'auteur entend par "Antiquité» une époque pour laquelle des sources écrites sont disponibles, soit environ 1.000 ans av. J.C.

2. Voir la traduction française de cet ouvrage : R. MATHIEU. Études sur la mythologie et l'ethnologie de la Chine ancienne. Paris. Collège de France. Institut des Hautes Études Chinoises, 1983, 2 vol.

3. Ils ne poussent guère aujourd'hui dans cette région : une température plus élevée permettait alors leur croissance.

4. J. GERNET. « Comportements en Chine archaïque ». Les Annales, 1952, I, pp. 31-38.

5. LIU Dunyuan. "Zhongo lishi shiqi xixiang de fenbu ji qi bianqian », in ZHANG Zhongge, ZHU Xianhuang (eds). Zhongguo xumu shi liaoji, Pékin. Kexue chubanshe. 1986. pp. 327-345. (Evolution et répartition des rhinocéros et éléphants en Chine durant la période historique).

6. Voir note 5.

7. ZHU KEZHEN. «Zhongguo jin wuqian nian laiqihou bianqian de chubu yanjiu », Kaogu xuebao. 1972. I, pp. 15-38. (Recherches préliminaires sur les variations climatiques en Chine durant les cinq mille dernières années).

\section{AUTEUR}

\section{GEORGES METAILIE}

Georges METAILIE est chargé de recherche au Muséum National d'Histoire Naturelle et au Collège de France. 